\title{
The stability constants, solubilities and solubility products of complexes of copper with dialkyldithiocarbamic acids
}

\author{
MATTHIJS J. JANSSEN \\ Orgenisch Chemisch Instjtuut T.N.O., Utrecht - Holland
}

\begin{abstract}
Dummary: A brief description is given of the methods used in the measurements of stability conatants, solublities and solublilty products of some copper dialkyldithiocarbamates and the renults are mentioned.
\end{abstract}

The complexing properties of dithiocarbamic acids have been known for fifty years [1]. No quantitative studies, however, have been reported on the stability constants of these complexes.

In this communication some measurements on the stability constants and solubility of copper dialkyldithiocarbamates are described.

Dithiocarbamic acid and $N$-substituted derivatives are unstable towards acids and the metal complexes have very low solubility in water. These obstacles have been overcome by the following procedure:

1) Spectrophotometrical determination of the stability constants in alkaline media by a competition method in which a second chelating agent with suitable properties was used [2].

2) Measurements were carried out in three ethanol/water mixtures and the results were extrapolated to water [3].

In the competition method mentioned 8-hydroxyquinoline and 8hydroxyquinoline-5-sulphonic acid were used as the competitive agents since the stability constants of the copper complexes of these compounds are comparable to those of sodium dialkyldithiocarbamate and could be determined spectrophotometrically with sufficient accuracy [4].

A disadvantage, however, is the formation of mixed complexes $C u O x D D C$ (in which $D D C$ stands for the dithiocarbamate anion and $O x$ for the competing ligand oxine or oxine sulphonic acid) which complicates the spectra in the competition experiments. Polydentate agents as EDTA do not show this behaviour but are undesirable for other reasons. 
The important equilibrium constants are the following:

$$
\begin{aligned}
& K_{1}=\frac{[C u D D C]}{[C u][D D C]} \\
& K_{2}=\frac{\left[C u D D C_{\mathrm{g}}\right]}{[C u D D C][D D C]} \\
& K_{\mathfrak{t}}=K_{1} K_{2} \\
& K_{t}^{\prime}=\frac{[\mathrm{CuOx}]}{[\mathrm{Cu}][O x]^{2}} \\
& K_{m}=\frac{[C u \cdot O x \cdot D D C]^{2}}{\left[C u D D C_{8}\right]\left[C u O x_{2}\right]} \\
& K_{c}=\frac{\left[C u D D C_{2}\right][O x]^{2}}{\left[C u O x_{2}\right][D D C]^{2}} \\
& K_{p}=\frac{[C u D D C]^{2}}{[C u]\left[C u D D C_{2}\right]} \\
& K_{t}=K_{c} K_{i} \\
& K_{p}=K_{1} / K_{2}
\end{aligned}
$$

The constant $K_{p}$ in combination with the result of the competition experiments allows the calculation of the successive stability constants.

$K_{m}$ gives the formation of the mixed complex from $\mathrm{CuDDC} \mathrm{C}_{\mathbf{2}}$ and $\mathrm{Cu}-$ $O x_{2}$ and has been measured by the method of continuous variations. The procedure of Hagenmuller [5] was used for the evaluation of this constant. With $K_{m}$ known we could proceed as follows: from $K_{m}$ the spectrum of the mixed complex is calculated and the spectra of the competition experiments are analysed for each component. This method is very time-consuming, however, and it is not quite clear how an uncertainty in $K_{m}$ affects the results.

It was more convenient to construct theoretical curves of the optical density against the fraction of $\mathrm{Cu}$ complexed to $D D C$ as is shown in fig. 1 .

The straight line (which represents the behaviour of the optical density when no mixed complex is formed) is corrected with the aid of the continuous variation curves determined earlier by simply adding the deviations found there. The resulting curve is compared with optical densi-

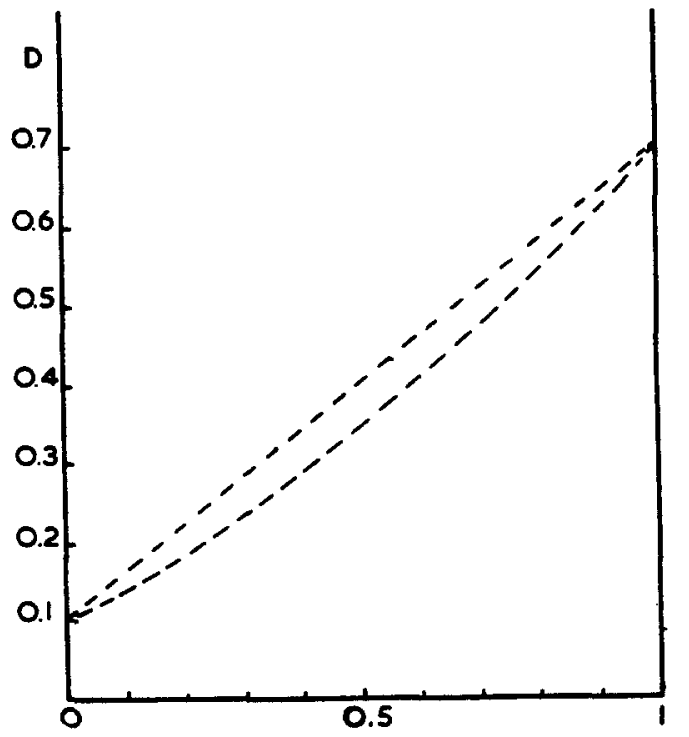

FRACTION OFCU BOUND TO NADDC

Fic. 1. - The optical density as a function of the fraction of copper bound to $D D C$ for a concentration of $10^{-6}$ $M C u$ in $5 \mathrm{~cm}$ cuvettes. Left $10^{-5} M C u O x_{2}$. Right $10^{-5} M C u D D C_{1}+2 \times 10^{-5} M O x$. 
ties measured in the competition experiments (after a correction is made when an excess oxine is present). From the fraction of copper bound to $D D C$, thus derived, the true concentrations of $C u O x_{2}$ and $C u D D C_{2}$ can be calculated with the aid of $K_{m}$ [2]. It can easily be shown that a large error in $\log K_{m}$ (about $0.4 \log$ unit) has only a small influence on $\log K_{c}$ (about $0.1 \log$ unit). $K_{\mathrm{c}}$ and thence $K_{\mathrm{t}}$ are calculated and as the evaluation of $K_{p}$ is quite straightforward, all constants of interest are known. Results in 68.4 weight percent of ethanol are shown in Table $\mathrm{I}$.

TABLE I. - Stability constants of copper dialkyldithiocarbamate complexes in $68.4 \%$ ethanol. $\log K_{t}^{\prime}=27.4$.

\begin{tabular}{c|c|c|c|c}
\hline \hline Dithiocarbamate & $\begin{array}{l}\log K_{t} \\
=\log K_{c} K_{t}\end{array}$ & $\log K_{D}$ & $\log K_{l}$ & $\log K_{1}$ \\
\hline N,N-dimethyl- $\ldots \ldots$ & 27.8 & 1.1 & 14.4 & 13.4 \\
N,N-diethyl- . . . & 28.8 & 0.9 & 14.9 & 13.9 \\
N,N-dipropyl- . . . & 29.3 & 0.9 & 15.1 & 14.2 \\
N,N-dibutyl- . . . & 29.4 & 0.9 & 15.2 & 14.2 \\
N,N-cgelotetramethylene- & 26.8 & 1.0 & 13.9 & 12.9 \\
N,N-eyclopentamethylene- & 28.4 & 1.1 & 14.7 & 13.7
\end{tabular}

It is remarkable that there are appreciable differences when the alkyl substituents are altered, cyclotetramethylenedithiocarbamic acid having the smallest, dibutyldithiocarbamic acid the greatest value.

Table II shows the results of $K_{t}$ and $K_{p}$ for other ethanol/water mixtures.

TABLE II. - Stability constants of copper dialkyldithiocarbamates at $20^{\circ} \mathrm{C}$ and $\mu=0.01$.

\begin{tabular}{|c|c|c|c|c|c|}
\hline \multirow{2}{*}{ Dithiocarbamate } & \multirow{2}{*}{ Constant } & \multicolumn{4}{|c|}{ Weight percentage of alcohol } \\
\hline & & 84.5 & 68.4 & 44 & $\mathbf{0}$ \\
\hline N,N-dimethyl $\cdot \cdots \cdot$ & $\begin{array}{l}\log K_{t} \\
\log K_{D}\end{array}$ & $\begin{array}{r}29.5 \\
1.3\end{array}$ & $\begin{array}{r}27.7 \\
1.1\end{array}$ & $\begin{array}{r}25.7 \\
0.6\end{array}$ & $\begin{array}{r}21.7^{\star 4} \\
1.1^{\star 4}\end{array}$ \\
\hline N,N-dipropyl $\quad \cdot \cdots \cdot$ & $\begin{array}{l}\log K_{t} \\
\log K_{p}\end{array}$ & $\begin{array}{r}31.0 \\
1.2\end{array}$ & $\begin{array}{r}29.4 \\
0.9\end{array}$ & $\begin{array}{r}27.6 \\
0.5\end{array}$ & $\begin{array}{r}24.0^{-4)} \\
\left.1.0^{\infty}\right)\end{array}$ \\
\hline N-cyclotetramethylene . . & $\begin{array}{l}\log K t \\
\log K_{p}\end{array}$ & $\begin{array}{r}28.4 \\
1.2\end{array}$ & $\begin{array}{r}26.8 \\
1.0\end{array}$ & $\begin{array}{r}24.7 \\
0.5\end{array}$ & $\begin{array}{r}20.82) \\
1.09)\end{array}$ \\
\hline $\begin{array}{l}\text { N,3-carboxycyclo-penta- } \\
\text { methylene . . . . }\end{array}$ & $\begin{array}{l}\log K_{t} \\
\log K_{p}\end{array}$ & $\begin{array}{r}31.0 \\
1.4\end{array}$ & $\begin{array}{r}29.0 \\
1.2\end{array}$ & $\begin{array}{r}26.8 \\
0.9\end{array}$ & $\begin{array}{r}22.4 \\
1.5\end{array}$ \\
\hline
\end{tabular}

(a) Extrapolated values. 
A study of the compound 3-carboxy-pentamethylenedithiocarbamate,<smiles>O=C(O[Na])C1CCN(S(=O)(=O)[O-])CC1</smiles>

was also made since this compound gives water-soluble copper complexes whereas the carboxyl group obviously cannot interfere directly with its complexing properties. The behaviour of this compound was of great use in the extrapolation. The extrapolated values for water are also indicated in Table II. The extrapolations themselves are shown in fig. 2 .

Nearly straight lines are obtained when the constants are plotted against the weight percentage of ethanol; when the ponts at $68.4 \%$ are somewhat displaced (for all dithiocarbamates equally) the graphs become wholly linear which facilitates the extrapolation and gives some trust to the values in water, especially since the carboxypentamethylene compound shows that the straight line in this case extends itself till pure water.

For the measurements of the solubility of these complexes the relevant equilibria are:

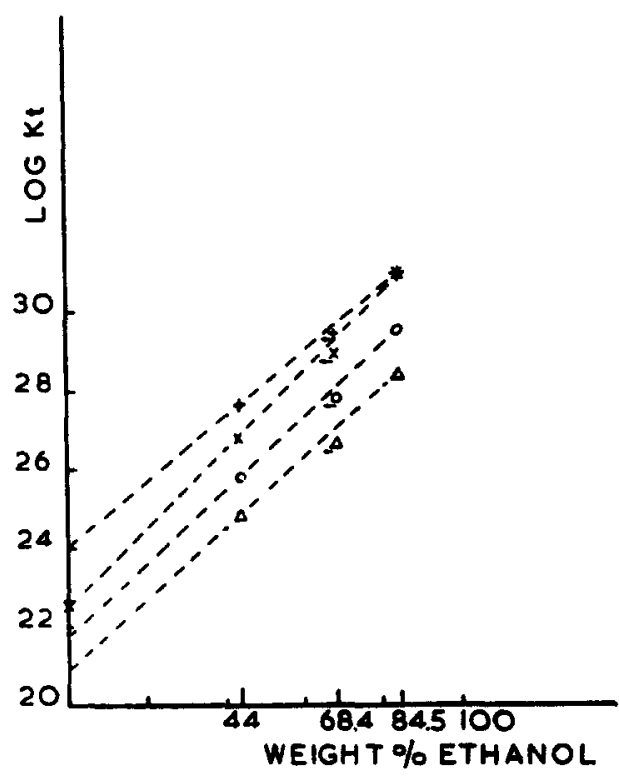

Fig. 2. - Extrapolation of $K_{t}$

$+N, N$-dipropyl-dithlocarbamate

o N,N-dimethyldithiocarbamate

$\Delta N$-cyclo-tetramethylenedithiocarhamate

x 3-carboxypentamethylenedithiocarbamate

$$
\begin{aligned}
& K_{\mathfrak{p}}=\frac{[C u D D C]^{2}}{[C u]\left[C u D D C_{2}\right]} \text { with }\left[C u D D C_{2}\right]=c_{s} \\
& K_{\mathfrak{p}} \cdot c_{\mathrm{s}}=\frac{[C u D D C]^{2}}{[C u]} \\
& \pi=[C u][D D C]^{2}=c_{s} . K_{t}^{-1}
\end{aligned}
$$

in which $c_{8}$ is the concentration of $C u D D C_{2}$ in a saturated solution and $\pi$ the solubility product of $\mathrm{CuDDC}$.

It is clear that the solubility $c_{s}$ can be evaluated when $K_{p}$ is known. 
Sollid $C u D D C_{2}$ was shaken with an aqueous solution of copper perchlorate and the concentration of $C u D D C$ was measured after filtration. The equilibrium was also approximated from the other side: $N a D D C$ was added to a large excess of $\mathrm{Cu}\left(\mathrm{ClO}_{4}\right)_{\mathbf{2}}$ and the precipitate was filtered after some time. After 24 hours both methods gave the same result so that the equilibrium was reached. From the measured concentration of $\mathrm{CuDDC}$ and the stoichiometrical concentrations of copper perchlorate and $\mathrm{NaDDC}$ the copper concentration can be derived and $c$, is calculated since $K_{p}$ is known (Table II). With the aid of the extrapolated stability constants the solubility products can also be calculated. A summary of the results is given in Table III.

TABLE III. - Solubility of copper dithiocarbamates $\left(20^{\circ} \mathrm{C}\right)$.

\begin{tabular}{c|c|c|c|c}
\hline Dithlocarbamate & $\log K_{p} . c_{8}$ & $\log K_{p}$ & $\log c_{8}$ & $\log \pi$ \\
\hline N-Ndimethyl- $\ldots \ldots$. & $0.4-7$ & 1.1 & $0.3-8$ & -29.4 \\
N,N-diethyl- $\ldots \ldots .$. & $0.6-8$ & 1.0 & $0.6-8$ & {$[-31]$} \\
N,N-dipropyl- . . . & $0.0-8$ & 1.0 & $0.0-9$ & -33.0 \\
N-cyclotetramethylene- . & $0.2-8$ & 1.0 & $0.2-8$ & -29.6 \\
N-cyclopentamethylene- & $0.2-8$ & 1.0 & $0.2-8$ & {$[-31]$}
\end{tabular}

This method is of general use for the determination of solubilities of complexes of the $M L_{2}$ type since an analysis of the content of total $M$ and total $L$ in the filtered solutions already is sufficient as the concentration of $M L_{2}$ can be neglected to a good approximaton. in most cases the constant $K_{p}$ can be measured without much trouble. (For rough estimations even an assumed value of 1 for $\log K$, generally is quite a good guess). The results of the solubility measurements support the assumption made by Irving and Williams [6] that inner complexes in the sense of Werner have an intrinsic solubility as such and are not completely dissociated in solution. The same effect has also been found by Traedwell for $A g_{2} s$ [7].

\section{REFERENCES}

[1] M. Delzpmw, * Bull. Soc. Chim. France * [4] \& 643, 652 (1908).

[2] M. J. Janssen, \& Rec. Trav. Chim. , 75, 1411 (1956).

[3] M. J. Janssen, * Rec. Trav. Chim. * 76, 827 (1957).

[4] M. J. Jasrsskn, Rec. Trav. Chim. "76, 1397 (1956).

[5] P. Hagenuuller, "Ann. Chim. [12] 6, 5 (1951).

[6] H. IRvino and R. J. P. Wrilinus, - Analyst , 7\%, 813 (1952).

[71 W. O. Traedwell and H. Hepenstricx, Melv. Chim. Act , 82, 1872 (1949). 


\section{IS CI:S I O N S}

Dyrseen (Stockholm) - In think the exprolation from $44 \%$ ethanol to zero \% with a straight line is rather dangerous. The constants in pure water may, however, be checked with the distribution method (cl. Dyrssen, Svensk Kem. Tidsks. 68212 (1956). If the distribution constant $\left(\lambda_{2}\right)$ for the uncharged complex, $C u(D D C)_{2}$, is too large for chloroform or carbon tetrachloride, an oxygen-containing solvent such as methyl isobutyl ketone (hexone) may be used. The distribution curve will then give $K$, and $K_{2}$ (and $\left.\lambda_{1}\right)$. From the solubility of $C u(D D C)_{2}$ in the organic solvent and $\lambda_{2}$ the solubility in pure water $(2 \%$ hexone) may be estimated.

Janecen - In view of the very low solubility of the copper dithiocarbamates in water, I think it would be necessary to use a solvent with a rather high distribution coefficient in order to get concentrations which can be determined spectrophotometrically and this would mean the use of very high concentrations of copper ions in the water phase. So I do not think this approach is useful in the case of these copper complexes. Of course, if we could work with radioactive compounds it would be a very good method. As far as the extrapolation is concerned, we had no choice but I think the inclusion of the compound with $C O O H$ group gave some justification to the dependance at lower ethanol concentrations.

Selhwarzenbech (Zürich) - Can oxyquinoline really compete with dithiocarbamate? My feeling was that the latter should form complexes of much higher stability.

Janacen - They do indeed in acid or neutral solutions, but in rather strong alkaline media (about $0,01 \mathrm{~N} \mathrm{NaOH}$ ) the complexing properties are comparable. Dithlocarbamic acids are rather strong, so there is no competition with hydrogen ions as with oxyquinoline. 